\title{
Understanding Socioeconomic Disparities in Travel Behavior during the COVID-19 Pandemic
}

\author{
Rebecca Brough, Matthew Freedman, and David C. Phillips *
}

June 2020

\begin{abstract}
We document the magnitudes of and mechanisms behind socioeconomic differences in travel behavior during the COVID-19 pandemic. We focus on King County, Washington, one of the first places in the U.S. where COVID-19 was detected. We leverage novel and rich administrative and survey data on travel volumes, modes, and preferences for different demographic groups. Large average declines in travel, and in public transit use in particular, due to the pandemic and related policy responses mask substantial heterogeneity across socioeconomic groups. Travel intensity declined considerably less among less-educated and lower-income individuals, even after accounting for mode substitution and variation across neighborhoods in the impacts of public transit service reductions. The relative inability of less-educated and lower-income individuals to cease commuting explains at least half of the difference in travel responses across groups.
\end{abstract}

JEL Codes: R41, J61, H12

Keywords: COVID-19, coronavirus, mobility, transportation, commuting, inequality

*Brough: University of Notre Dame (e-mail: rbrough@nd.edu). Freedman: University of California, Irvine (e-mail: matthew.freedman@uci.edu). Phillips: University of Notre Dame (e-mail: david.phillips.184@nd.edu). This research was supported by the University of Notre Dame's Wilson Sheehan Lab for Economic Opportunities (LEO). Survey data collection was supported by the Institute for Research on Poverty and the JPB Foundation. Special thanks to SafeGraph and King County Metro for providing data and to the University of Wisconsin Survey Center for completing phone surveys. We also thank many individuals throughout King County government who provided valuable feedback on this research. The views expressed here are those of the authors and do not necessarily represent the views of King County. Any remaining errors are the responsibility of the authors. 


\section{Introduction}

The novel coronavirus (COVID-19) has led to swift and unprecedented changes in people's travel behavior around the world. A combination of voluntary precautions and policy responses by governments, including city lockdowns and stay-at-home orders, have sharply curtailed trips for both work and leisure in many places, potentially helping to contain the spread of the virus. However, the ability of different groups of individuals to adjust their travel behavior in the face of the pandemic and various policy directives has raised important equity concerns.

In this paper, we study changes in travel behavior in response to COVID-19 in King County, Washington. King County is home to Seattle, one of the first cities in the U.S. affected by the pandemic and one with some of the earliest and most sweeping policy responses. Using anonymized geolocated cell phone data from SafeGraph Inc., we first document over-

all changes in travel in response to COVID-19 as well as how changes in mobility correlate with neighborhood disadvantage. Exploiting passenger boardings information derived from sensors on board King County Metro's fleet of vehicles, we go on to explore changes in public transit use in particular, and how those changes vary with neighborhood demographics. Supplementary administrative data on transit boardings by individuals using full-fare transit cards vs. reduced-fare cards available only to lower-income individuals shed additional light on the disparate responses by higher- and lower-income riders. Finally, we explore the mechanisms behind the differential changes in travel behavior among higher- and lower-income individuals. We take advantage of both administrative data and the results of a novel survey of low-income transit users in King County to uncover the sources of the observed changes in mobility across socioeconomic groups during the pandemic.

We document a steep decline in mobility in King County as the pandemic took hold. Based on cell phone tracking data, the average number of census block groups (CBGs) people visited each day (excluding their home CBG) fell by $57 \%$ between February and April 2020. During the same period, public transit use declined by an even sharper $74 \%$. 
These large average declines mask substantial heterogeneity across socioeconomic groups. Mobility responses were particularly swift, pronounced, and persistent among more highly educated and higher-income individuals.

We go on to examine the underlying mechanisms behind these changes in travel behavior across socioeconomic groups. We focus specifically on the roles of transportation mode substitution, public transit service adjustments, and commuting for work.

First, residents of more-educated neighborhoods engaged in a greater degree of mode substitution, but only early on in the crisis. During the initial stages of King County's lockdown, we observe a differentially large decline in public transit use relative to overall travel in highly educated neighborhoods. This implies that high-income residents disproportionately shifted away from public transit and toward cars. However, the role of mode substitution in driving differences in travel behaviors across socioeconomic groups has faded over time, suggesting a convergence in substitution elasticities.

Second, public transit service adjustments in the aftermath of the lockdown can explain only a small fraction of the gap in transit use between higher- and lower-income riders. Between mid-March and mid-April, King County transit authorities limited service in various parts of the local public transportation system. To the extent that these service adjustments differentially affected residents of more- vs. less-educated neighborhoods, it could help to explain the differential response in travel behavior we observe between groups. However, ridership of higher-income users relative to lower-income users declines as much or more within transit routes as between transit routes, indicating that the supply of public transit plays little role in driving differential changes in transit use across socioeconomic groups.

Finally, we find that the relative inability of less-educated and lower-income people to work remotely is likely an important contributor to the smaller mobility response for that group. In the depths of the lockdown, weekly and daily cycles of travel consistent with commuting for work remain conspicuous among residents of less-educated neighborhoods and among individuals using reduced-fare public transit cards. For residents of more-educated 
neighborhoods and individuals using regular-fare public transit cards, commute cycles are clear in the data before the crisis but largely vanish after the pandemic took hold. ${ }^{1}$ Under the conservative assumption that weekday trips are for work and weekend trips are for other activities, the magnitude of this change indicates that at least half of the socioeconomic gap in travel reductions is attributable to commuting for work.

We complement these results using newly collected survey data from an ongoing study in King County. The survey highlights how intended uses of transit changed among low-income individuals as the COVID-19 crisis took hold. We find that low-income individuals consistently report intentions to use transit for activities that could be deemed essential, such as for work, school, and health, even as the crisis and its policy response unfolded. Meanwhile, intentions among low-income individuals to use transit to travel for recreational, family, shopping, and other reasons trailed off after the first local viral outbreaks and continued to decline as the policy response materialized.

Our results add to the growing body of evidence suggesting that the burden of the pandemic, not only in terms of its direct health effects but also in terms of the economic costs of avoidance and mitigation efforts, are spread unevenly across demographic groups. Several recent papers have identified COVID-19's disparate effects along other dimensions. For example, Abedi et al. (2020) shows that the virus' incidence varies across demographic groups in the U.S. Borjas (2020) and Schmitt-Grohé et al. (2020) demonstrate that COVID19 testing rates vary systematically by neighborhood demographics in New York City. Baker et al. (2020) document heterogeneity in household consumption patterns across demographic groups and by income level in response to the pandemic. Adams-Prassl et al. (2020), Cajner et al. (2020), Fairlie et al. (2020), Montenovo et al. (2020), and Kahn et al. (2020) highlight how the economic costs of the crisis have been borne disproportionately by lower-income groups, for whom working remotely is less likely to be feasible and for whom income and job losses overall have been greater in the aftermath of the crisis.

\footnotetext{
${ }^{1}$ This pattern is particularly striking given that job losses among low-income people in the wake of the pandemic have been substantially larger than those among high-income people (Cajner et al. 2020).
} 
We contribute to this literature by illustrating heterogeneity in the mobility impacts of the crisis, which could represent both causes and consequences of many of the other documented disparate effects of the pandemic. To the extent that less-educated and lower-income groups continue to travel at higher rates than more-educated and higher-income groups (especially in modes frequently necessitating interaction with other people, like public transit), it could contribute to higher viral transmission rates among those groups. The higher mobility among less-educated and lower-income groups is also potentially a consequence of their inability to work remotely and home conditions that are generally less hospitable to sheltering in place due to lack of adequate internet access, space constraints, and limited access to outdoor areas.

Our results have important policy implications. The relatively inelastic mobility response to COVID-19 among less-educated and lower-income groups does not appear to be primarily a result of a failure of messaging or differences in the degree to which they comply with directives regarding non-essential travel. Rather, our findings suggest that their more muted mobility response arises from economic necessity, and in particular the need to travel to jobs that cannot be performed remotely. To the extent that policymakers might desire to reduce mobility among these groups further to address public health concerns, changes in public communication strategies or stricter enforcement of rules regarding non-essential travel may have only modest effects. Changes in what operations are deemed essential, and thus which workers are expected to be physically present at jobs during pandemics, could go further in reducing disparities in travel behavior. Raising the opportunity cost of traveling for work via transfers tied to staying home (for example, through the unemployment insurance system) could also potentially reduce these disparities. However, such measures could come at the cost of forgoing certain, possibly critical, goods and services during the crisis, and might translate into even larger job losses among individuals at the lower end of the income distribution.

Our findings also help to foreshadow possible changes in mobility patterns and modes 
as local economies reopen. The large and persistent drop in public transit use relative to overall mobility points to substitution away from modes that involve close proximity to others and toward those that do not (e.g., single-occupancy driving). To the extent that this persists, it could have important implications for traffic congestion and pollution, especially as lockdown orders are lifted. There also may be a lasting shift to remote working for some types of jobs (Lavelle 2020, Molla 2020), which could generate more persistent disparities in travel behaviors to the extent that people in different socioeconomic groups hold jobs that can be performed remotely at different rates.

\section{Mobility Responses to the COVID-19 Pandemic}

\subsection{The King County Context}

We focus on King County, Washington. King County was among the first U.S. locations impacted by the pandemic, and thus has one of the longest post-COVID-19 periods to analyze. The first confirmed COVID-19 case on U.S. soil was identified in the state of Washington on January 21, 2020, and one of the first COVID-19-related deaths occurred in the Seattle area on February 28. The outbreak of COVID-19 at the Life Care Center in Kirkland, a suburban area in King County just east of Seattle, in late February set the wheels in motion for sweeping state and local government policy responses. The Seattle mayor issued a proclamation of civil emergency on March 3. Public schools as well as restaurants, bars, and entertainment facilities statewide were closed March 16. The state issued its official stay-at-home order March 23, two days before all nonessential businesses in the state were forced to close.

King County also provides data that uniquely speak to travel patterns in general and differences in travel behavior by income in particular. First, we have access to multiple sources of transit ridership information in King County. Through a partnership with King County Metro, we have data on passenger counts derived from sensors on board most King 
County buses. We also have separate, individual-level boarding data based on "taps" by transit fare cards. Taps by regular-fare and reduced-fare cards allow us to track trips by higher- and lower-income riders separately.

Second, we were in the midst of a randomized controlled trial studying transit fare policy when COVID-19 cases began to emerge in the U.S. and when King County went into lockdown. ${ }^{2}$ That study included surveys that provide detail on travel intentions and behavior during the shutdown.

\subsection{Changes in Overall Mobility}

We use data from SafeGraph Inc. to measure overall changes in travel intensity as the COVID-19 crisis unfolded. SafeGraph tracks the locations of millions of mobile devices on which individuals have agreed to allow applications to access data on their precise locations. These data are anonymized and aggregated to CBGs. SafeGraph determines a device's home CBG based on where it resides most frequently. Using origin and destination information, the SafeGraph data allow us to construct high-frequency measures of mobility among individuals. $^{3}$

In King County, we observe around 100,000 devices in the SafeGraph data, or about 78 devices per CBG. Assuming each device is attached to one individual, this corresponds to a roughly $5 \%$ sample of all individuals living in King County. Coverage rates are not strongly correlated with socioeconomic characteristics of a neighborhood. ${ }^{4}$ Our primary measure of mobility derived from the SafeGraph data is the average number CBGs visited each day, other than the home CBG, per device. We focus primarily on the relationship between travel behavior and the share of adult residents in a CBG with a bachelor's degree because it is one of the strongest predictors of changes in travel intensity between February and April

\footnotetext{
${ }^{2}$ See Brough et al. (2020b) for results from a pilot phase of that study.

${ }^{3}$ More information about the SafeGraph data can be found here: https://docs.safegraph.com/docs/socialdistancing-metrics.

${ }^{4}$ The number of devices per resident in a CBG is correlated with neither median income $(r=0.01)$ nor fraction white $(r=0.02)$. The fraction with a bachelor's degree has a slightly greater, but still weak, negative correlation with devices per person $(r=0.19)$. See the scatterplot in Appendix Figure 1.
} 
Travel intensity overall fell enormously throughout King County during the lockdown, but fell particularly sharply in neighborhoods with high average levels of education and income. Panel (a) of Figure 1 shows the percent change in the SafeGraph measure of travel intensity between February and April across CBGs in King County. The average percent decline across all CBGs in the county was $57 \%$, but this average masks substantial heterogeneity. The more lightly shaded areas had larger reductions in overall travel intensity as measured by cell phone location tracking. The lighter areas are concentrated in northwestern King County, where more highly educated and higher-income households reside.

Panel (b) of Figure 1 correlates the percent change in travel intensity among residents of a CBG between February and April with the fraction of that CBG's residents that have a bachelor's degree. As the figure shows, the decline in overall mobility among residents of less-educated CBGs is substantially smaller in magnitude than the decline among residents of more-educated CBGs. Column (1) of Table 1 quantifies this relationship. A CBG where 10\% of the residents have a bachelor's degree sees on average a $45 \%$ decline in overall mobility, whereas a CBG where $90 \%$ of residents have a bachelor's degree sees on average a $69 \%$ decline. As Appendix Table 1 shows, we find a similar relationship with CBG income levels; every additional $\$ 100,000$ in median income in a CBG is associated with a 13 percentage point larger decline in mobility. Appendix Table 1 also demonstrates that the correlation between neighborhood education and the decline in travel is robust to controlling for income and several other neighborhood demographic and economic characteristics. Moreover, this correlation is new; Appendix Figure 2 shows no relationship between neighborhood education level and the January-February change in travel.

\footnotetext{
${ }^{5}$ We run a LASSO model for a cross-section of CBGs with the percent change in travel intensity as the outcome and various CBG characteristics as predictors. The full list of CBG characteristics we use as predictors appears in the notes to Appendix Table 1 (in reference to column (4)). Only the share of residents with a college degree and the share of residents working in the technology sector survive the LASSO.
} 


\subsection{Changes in Public Transportation Use}

\subsubsection{Neighborhood-Level Measures of Transit Use}

We take advantage of King County Metro automated passenger counter (APC) data to study changes in public transit use across neighborhoods. The APC data are based on information collected from sensors installed on a subset (approximately 70\%) of buses that run in King County. These sensors track boardings, which we aggregate to CBGs in a manner similar to how SafeGraph data are aggregated. We examine how boardings in each CBG change over time and by neighborhood characteristics.

Across CBGs, the average percent decline in transit boardings between February and April was $74 \%$, about a $30 \%$ larger decline than that for overall travel during the same period. Again, the large average decline in transit use across CBGs obscures significant heterogeneity. As shown in column (3) of Table 1, a ten percentage point higher share of residents with a bachelor's degree is associated with a 3.1 percentage point larger drop in public transit use. Appendix Figure 3 shows the scatterplot of this relationship and maps the decline in transit use. Replicating the results for overall travel intensity, Appendix Table 3 documents that the drop in boardings also correlates with income. Every additional $\$ 100,000$ in median income in a CBG is associated with a 17 percentage point larger decline in mobility.

\subsubsection{Individual-Level Measures of Transit Use}

We obtained administrative data on boardings among King County Metro customers who used transit cards to pay their fares on local public transportation. These cards include regular, adult-fare "ORCA" transit cards (of which there are millions in circulation) as well as reduced-fare "ORCA LIFT" transit cards available only to low-income riders (of which there are over 50,000 in circulation). ${ }^{6}$ Taps by ORCA and ORCA LIFT cards allow us to

\footnotetext{
${ }^{6}$ ORCA LIFT cards are available to any household with income less than $200 \%$ of the federal poverty line. People enroll in LIFT by requesting a card in-person at public and social service agencies, which verify income prior to issuing the card.
} 
track trips by higher- and lower-income riders separately. However, unlike the APC data, ORCA records omit people who pay by cash or who evade payment.

Notably, King County Metro eliminated fares on all its buses, light rail, and other routes on March 21, 2020 to ensure social distancing protocols among customers and drivers could be maintained. Therefore, we do not have data on taps using ORCA or ORCA LIFT cards after that date. ${ }^{7}$

We see a large overall decline in public transit trips using fare cards as the crisis began to unfold in early March. Again, however, the decline was more marked for higher- relative to lower-income riders. Column (5) of Table 1 shows the results. Comparing boardings in February to mid-March, regular ORCA rides fell by $51 \%$, whereas LIFT rides fell by only $32 \%$. Hence, these individual-level data corroborate the neighborhood-level data in showing a sharply heterogeneous mobility response to COVID-19 by socioeconomic group.

\section{Mechanisms}

Overall travel intensity fell more sharply for residents of high-education than low-education neighborhoods in the face of the COVID-19 pandemic in King County. Measured changes in public transportation use specifically were particularly large among more highly educated and higher-income individuals. We next turn to a deeper investigation of potential mechanisms underlying the differences in travel responses to COVID-19 across socioeconomic groups.

\subsection{Reliance on Different Modes}

We first consider the role of transportation mode substitution during the COVID-19 crisis. From a distributional perspective, examining transportation mode is important for at least two reasons. First, low-income people tend to rely more heavily on public transit (Glaeser et

\footnotetext{
${ }^{7}$ For comparison, we show in Appendix Tables 2 and 4 the change in overall travel as measured in the SafeGraph and APC data between February and mid-March. Qualitatively, the results are very similar to those discussed above.
} 
al. 2008). Second, COVID-19 itself and policy responses to it may differentially affect travel by transit versus other modes. Transit is more likely to facilitate viral transmission, which may lead people to avoid it during a pandemic. To the extent that high-income individuals have greater access to means of transportation other than public transit, mode substitution as an avoidance strategy may be more feasible for those individuals. In that case, we would expect to see a larger decline in public transit use than in overall travel for high-income individuals than we see for low-income individuals.

A key result from above is that transit use decreases more than travel overall. Thus, in light of the fact that less-educated and lower-income individuals rely disproportionately on public transit, reliance on different modes alone cannot explain the overall mobility gap that emerges during the crisis between high- and low-income travelers. Instead, the larger decrease in transit use suggests that many individuals engaged in transportation mode substitution (e.g., away from public transit and toward cars or other modes) in response to the pandemic.

However, while the degree of mode substitution differed across socioeconomic groups early on in the pandemic, our results indicate that differential mode substitution does not drive differences in travel behavior in the shutdown steady state. Between February and April, a neighborhood where $90 \%$ of residents hold bachelor's degrees experienced a $69 \%$ decrease in overall mobility compared to an $86 \%$ percent decrease in transit boardings. Therefore, transit use is about $25 \%(1-.86 / .69)$ more responsive than overall travel in high-education neighborhoods. In a neighborhood where $10 \%$ of residents hold bachelor's degrees, transit responds by $36 \%$ more than travel overall (a $61 \%$ vs. a $45 \%$ drop). If anything, the relative drop in transit use is about $8 \%$ smaller in high-education neighborhoods.

During the transition, however, mode substitution did differ by socioeconomic status. Between February and mid-March, transit fell by $45 \%$ more than travel overall in higheducation neighborhoods ( $64 \%$ vs. $44 \%$ ). Transit fell by only $26 \%$ more than travel overall in low-education neighborhoods during the same period (24\% vs. 19\%). Thus, individuals in high-education neighborhoods substituted away from transit to other modes of travel more 
than individuals in low-education neighborhoods during the early stages of the shutdown. However, this gap disappeared or even reversed as the crisis deepened.

\subsection{Supply of Public Transportation}

One possible explanation for the differences in the magnitudes of the decline in overall travel intensity, and in public transit use in particular, between higher- and lower-income King County residents are public transit service adjustments. Unlike other forms of transportation, policymakers directly control the volume of transit by mapping routes and setting service frequency. In the face of the pandemic, King County Metro limited service in various parts of its system. King County Metro announced its first reductions in service on March 23, 2020. By mid-April, Metro had made three rounds of service adjustments; at that point, Metro was operating $27 \%$ fewer service trips than typical weekday service (Switzer 2020). Policy decisions could drive differences in travel behavior if they leave open bus lines in lowincome neighborhoods that rely on transit while closing them elsewhere. Transit also requires a minimum volume to operate efficiently; even a reduction in service responding to lower passenger volume during a lockdown could amplify any differences across neighborhoods that appear for other reasons.

While service changes may have reduced transit ridership, we find no evidence that this widened the gap in travel behavior between higher- and lower-income riders. In the transit data, we can compare how full-fare ORCA and low-income LIFT riders who ride the same route respond to COVID-19. If a reduced supply of transit drives lower passenger volume, then higher- and lower-income riders on the same route should respond similarly. Figure 2 displays these data. Each circle in the figure represents a Metro route, with bigger circles corresponding to more popular routes. The figure plots the percent change in LIFT boardings on each route between February and mid-March against the percent change in full-fare boardings on the same route during the same period. Nearly all routes are below the 45 degree line, indicating that high-income boardings decrease more than low-income 
boardings within routes. Formally, as shown in columns (5) and (6) of Table 1, when we control for route fixed effects in a regression of the percent change in boardings on a LIFT dummy, the coefficient of the LIFT dummy does not change statistically and actually increases in magnitude slightly. This implies that variation across neighborhoods in the impacts of public transit service reductions do not drive the disparities in changes in transit use across socioeconomic groups. ${ }^{8}$

\subsection{Commuting}

Constraints on lower-income individuals' ability to work remotely could limit their decline in travel. According to Dingel and Neiman (2020), approximately $42 \%$ of Seattle area jobs can be performed at home. Mongey et al. (2020) find that nationwide, jobs that do not permit working remotely and jobs that involve high physical proximity tend to be held by individuals that are less educated, have lower income, and are more credit constrained. A disproportionate number of less-educated residents could also be commuting to work at businesses deemed essential and permitted to stay open during the lockdown. ${ }^{9}$ Kearney and Pardue (2020) find that, due to essential business exceptions, lower-educated and minority workers are disproportionately likely to be traveling to work during city lockdowns relative to working from home.

We find three pieces of evidence suggesting that differential degrees of remote working across socioeconomic groups represent a key mechanism driving differences in travel behavior during the pandemic.

\footnotetext{
${ }^{8}$ Transit service reductions in King County were almost entirely effected by route eliminations and frequency changes as opposed to route adjustments. While changes in stop locations within routes are not a likely source of differences in transit use reductions across socioeconomic groups, to the extent that higherand lower-income riders were differentially affected by frequency changes, that could contribute to observed disparities. The most likely concern is that differing service reductions by time of day create the gap. However, we show in Appendix Table 6 that the results remain within any given time of day.

${ }^{9}$ For information on which types of businesses were deemed essential, see https://coronavirus.wa.gov/what-you-need-know/whats-open-and-closed/essential-business.
} 


\subsubsection{Weekly Travel Cycles}

First, the weekly cycle of travel attenuates more for high-income people than for low-income people in the aftermath of the crisis. In Panels (a)-(c) of Figure 3, we show daily time series for travel from all three data sources (SafeGraph, APC, and ORCA). For the SafeGraph and APC data, we break out the data based on whether a CBG's share of residents with a bachelor's degree is above vs. below the median share. For the ORCA data, we split results based on whether the card used is a full-fare ORCA card or a reduced-fare LIFT card.

Based on the SafeGraph data (Panel (a) of Figure 3), prior to March, daily travel among residents of more- and less-educated CBGs tracks closely. In early March, however, travel begins to taper, particularly among residents of more-educated CBGs. This tapering began soon after the Life Care Center Outbreak was detected in late February and as local social distancing directives were issued, but well before all schools closed and the state's stay-athome order went into effect. Travel continued to decline, and the gap between residents of more- and less-educated areas continued to grow, as the policy response materialized.

Most notably, we observe that the pre-COVID-19 weekday versus weekend cycle of trips persists to a greater extent among residents of less-educated CBGs than among residents of more-educated CBGs post-COVID-19. In other words, less-educated and lower-income individuals not only traveled more in general as the COVID-19 crisis unfolded, but they traveled more particularly between Mondays and Fridays each week. This suggests that requirements of their jobs contributed to the more muted travel response for these groups. The fact that the weekend travel declines among residents of less-educated neighborhoods more closely matched those of residents of more-educated neighborhoods suggests that differences in travel for recreational or other non-work related purposes is unlikely to be the primary driver behind the overall observed differential decline between groups.

In Panel (b) of Figure 3, we show average daily public transit boardings across CBGs by education level using the APC data. The transit data show a more pronounced weekly pattern than the overall travel data, reflecting the fact that many individuals in King County 
regularly use transit to get to work but not necessarily for other types of trips. Average boardings per resident are also very similar across high- and low-education neighborhoods prior to March. However, the post-COVID-19 patterns of decline and the growing gap in use between residents of more- vs. less-educated CBGs echo those observed in the SafeGraph data. The weekly cycle of public transit boardings remains more conspicuous for residents of lower-education CBGs than for residents of higher-education CBGs, again implying that much of the differential transit use among those living in low-education areas is for the purposes of traveling to work as opposed to for recreational or other purposes. ${ }^{10}$

We illustrate the time pattern of average boardings per day for ORCA and LIFT cardholders in Panel (c) of Figure 3. The pre-COVID-19 level differences in travel by rider income level are more pronounced in the individual-level data. However, consistent with the SafeGraph and APC data broken out by neighborhood education level, we see an earlier and sharper decline in transit use among regular ORCA cardholders than among LIFT cardholders. Because King County transit authorities eliminated fares on March 21, we do not observe a long post-COVID-19 period in these data. However, the data up to the point of fare elimination corroborate the patterns observed in the two other data sources.

Using the SafeGraph data, at least $54 \%$ of the gap between high- and low-income people can be attributed to work travel. Consider column (2) of Table 1 and neighborhoods with $90 \%$ and $10 \%$ of residents with bachelor's degrees. The coefficients imply that weekday ridership fell by $71 \%$ in the high-education neighborhood and $43 \%$ in the low-education neighborhood, for a gap of $28 \%$. On the weekend, the difference narrows to $13 \%$. Columns (4) and (7) show similar results for transit boardings as measured by automated passenger counters and ORCA card readers, respectively. Suppose we assume that the weekend effect represents the change in travel that happens every day for non-work reasons. Then, a week that experienced this effect every day would have an income gap of $13 \%$, or $46 \%$ of the true gap. The other $54 \%$ must be due to work travel. This is almost certainly a lower bound

\footnotetext{
${ }^{10}$ As Appendix Figure 4 shows, there were no such differential patterns of transit use over time in 2019.
} 
for the role of work travel. Low-income people are much more likely to work outside regular business hours and on weekends (Shierholz et al. 2012), so the true gap in non-work travel is probably narrower than just what we observe on weekends.

\subsubsection{Daily Travel Cycles}

A second piece of evidence in favor of differences in remote working as an explanation for disparities in travel behavior are patterns of travel by time of day. These patterns indicate that much of the relatively greater volume of travel among low-income residents of King County is occurring at times at which people are typically travelling to and from work.

Panels (d)-(f) of Figure 3 use the SafeGraph, APC, and ORCA data to illustrate the times of day people travel, broken out by month and by education level of the neighborhood (for the SafeGraph and APC data) or by income of the rider (for the ORCA data). ${ }^{11}$ In Panels (d) and (e), there is a clear hourly pattern of travel among residents of both higherand lower-educated neighborhoods in February; for example, in the SafeGraph data, the fraction of devices not observed in their home CBG rises from around $40 \%$ to near $80 \%$ within the span of a few hours each morning, then gradually falls back to $40 \%$ beginning in the late afternoon. Both lines flatten substantially by April, but more so for residents of higher income neighborhoods. There remains an evident hourly pattern of travel for residents of less-educated neighborhoods, particularly during peak evening travel hours. Similar but even more pronounced changes in travel within days are evident in the APC and ORCA data for public transit use.

\subsubsection{Survey Results}

As a third and final piece of evidence, we lean on direct survey responses of low-income transit riders. We were in the process of conducting a transit-related survey among low-income residents of King County when the COVID-19 pandemic emerged (Brough et al. 2020a).

\footnotetext{
${ }^{11}$ For these figures, we average data over only weekdays. Results are very similar if include weekends.
} 
The survey was given to individuals who agreed to participate in a study in which they had a chance of receiving free transit fares for a limited period of time. The eligible population included those who visited a Washington Department of Social and Health Services office in King County and who qualified for any public assistance program (e.g., SNAP, Medicaid, or TANF). Between December and March, 1318 individuals enrolled in our study and had provided details about their travel intentions in our intake survey. ${ }^{12}$

As the COVID-19 crisis deepened, low-income individuals consistently reported intentions to take trips for essential activities even as intentions to take trips for other activities diminished. All participants in our survey report the activities for which they expect to use the study transit card, allowing them to pick multiple items. We categorize these items into essential (work, school, public benefits, and health), commercial (shopping and errands), and social (recreation, family, religious/community, and other) activities. Figure 4 shows how the average number of activities the person selects in each category varies with the time of the report (which is tied to the timing of their public benefits office visit and enrollment in the study). During the first two months of 2020, all types of trips remain constant. At the onset of COVID-19, intentions to use transit for essential trips remains constant, but intentions to use transit for recreational, family, shopping, and other reasons trail off. Following up with a small sample of 119 participants beginning in March 2020 via phone and web travel surveys confirms these intentions. ${ }^{13}$ Most trips were for essential (28\%) or commercial (40\%) purposes. Only $32 \%$ are for family, religious, or recreational purposes.

These survey data corroborate our previous results based on weekly and daily travel patterns and point to commuting (as opposed to telecommuting) to work as an important factor driving differences in travel behavior across socioeconomic groups during COVID-19.

\footnotetext{
${ }^{12}$ See Appendix Table 7 for descriptive statistics for this sample.

${ }^{13}$ Surveying is in progress at the time of writing. Thus far, we have attempted to contact a representative sub-sample of 476 people, with a response rate of $25 \%$ among that group. See Appendix Table 7 for descriptive statistics for this sub-sample.
} 


\section{Conclusion}

In this paper, we examine socioeconomic differences in travel behavior during the COVID-19 pandemic in King County, Washington. Taking advantage of rich administrative data, we document large average declines in travel, and transit use in particular, in response to the pandemic and associated policy responses. However, the average declines mask substantial heterogeneity across socioeconomic groups. Even after accounting for mode substitution and differential public transit service reductions, travel intensity declined less among lesseducated and low-income individuals. Using a combination of administrative and survey data, we trace the differences in travel behavior between groups predominantly to the relative inability of less-educated and lower-income individuals to perform their jobs from home.

We add to the growing body of research documenting the disparate, and largely regressive, impacts of the COVID-19 crisis. Our results echo recent findings on, for example, the relatively worse health and labor market impacts of the COVID-19 pandemic for lesseducated and lower-income individuals (Abedi et al. 2020, Cajner et al. 2020, Montenovo et al. 2020). The disparities in travel behavior we identify in this paper could be both a cause and consequence of differences across socioeconomic groups in these other outcomes. A higher propensity to travel away from home during the pandemic could contribute to a greater prevalence of the virus among certain groups. Meanwhile, differential abilities to work remotely as an avoidance strategy could generate differences in travel behavior along education and income lines.

Notably, our results pertain to King County, which is home to a major city. They may not generalize to other settings, and in particular to rural areas with limited public transit options. Nonetheless, our findings have important immediate and longer-term policy implications. Our results suggest that disparities in travel behavior are less likely the result of a failure of messaging or of the enforcement of orders to refrain from non-essential travel (such as for recreation), and more likely the result of a need among individuals in some groups to travel for work. Our findings also may presage possible shifts in transportation 
modes and broader changes in mobility patterns as local economies reopen. The movement away from public transit may augur increases in road congestion and pollution as economic activity ramps up. To the extent that remote working becomes a permanent fixture for some companies, it could mitigate traffic congestion, but also increase disparities in travel behavior across socioeconomic groups if those companies tend to have relatively highly educated and high-income workforces. 


\section{References}

Abedi, Vida, Oluwaseyi Olulana, Venkatesh Avula, Durgesh Chaudhary, Ayesha Khan, Shima Shahjouei, Jiang Li, and Ramin Zand. 2020. "Racial, Economic and Health Inequality and COVID-19 Infection in the United States." medRxiv.

Adams-Prassl, Abi, Teodora Boneva, Marta Golin, and Christopher Rauh. 2020. "Inequalty in the Impact of the Coronavirus Shock: Evidence from Real Time Surveys." CEPR Discussion Paper DP14665.

Baker, Scott, Robert Farrokhnia, Steffen Meyer, Michaela Pagel, and Constantine Yannelis. 2020 "How Does Household Spending Respond to an Epidemic?" NBER Working Paper 26949.

Borjas, George. 2020. "Demographic Determinants of Testing Incidence and COVID-19 Infections in New York City Neighborhoods." NBER Working Paper 26952.

Brough, Rebecca, Matthew Freedman, and David C. Phillips. 2020a. "A (Free) Ticket to Ride: Experimental Evidence on the Effects of Means-Tested Public Transportation Subsidies." AEA RCT Registry, AEARCTR-0005538.

Brough, Rebecca, Matthew Freedman, and David C. Phillips. 2020b. "A (Free) Ticket to Ride: Experimental Evidence on the Effects of Means-Tested Public Transportation Subsidies." Working Paper.

Cajner, Tomaz, Leland D. Crane, Ryan A. Decker, John Grigsby, Adrian Hamins-Puertolas, Erik Hurst, Christopher Kurz, Ahu Yildirmaz. 2020. "The U.S. Labor Market During the Beginning of the Pandemic Recession." NBER Working Paper 27159.

Dingel, Jonathan, and Brent Neiman. 2020. "How Many Jobs Can Be Done at Home?" NBER Working Paper 26948.

Fairlie, Robert, Kenneth Couch, and Huanan Xu. 2020. "The Impacts of COVID-19 on Minority Employment: First Evidence from April 2020 CPS Microdata." NBER Working Paper 27246.

Glaeser, Edward, William Kerr, and Jordan Rappaport. 2008. "Why Do the Poor Live in 
Cities?" Journal of Urban Economics 63(1): 1-24.

Kahn, Lisa, Fabian Lange, and David G. Wiczer. 2020. "Labor Demand in the Time of COVID-19: Evidence from Vacancy Postings and UI Claims." NBER Working Paper 27061.

Kearney, Melissa, and Luke Pardue. 2020. "Exposure on the Job: Who are the Essential Workers Who Likely Cannot Work from Home?" Brookings Institution Report.

Lavelle, Justin. 2020. "Gartner CFO Survey Reveals 74\% Intend to Shift Some Employees to Remote Work Permanently." Gartner. April 3.

Molla, Rani. 2020. "Office Work Will Never Be the Same." Vox. May 21.

Mongey, Simon, Laura Pilossoph, and Alex Weinberg. 2020. "Which Workers Bear the Burden of Social Distancing Policies?" NBER Working Paper 27085.

Montenovo, Laura, Xuan Jiang, Felipe Lozano Rojas, Ian M. Schmutte, Kosali I. Simon, Bruce A. Weinberg, Coady Wing. 2020. "Determinants of Disparities in COVID-19 Job Losses." NBER Working Paper 27132.

Schmitt-Grohé, Stephanie, Ken Teoh, and Martín Uribe. 2020. "COVID-19: Testing Inequality in New York City." NBER Working Paper 27019.

Shierholz, Heidi, Lawrence Mishel, Elise Gould, and Josh Bivens. 2012. The State of Working America, 12th Edition. Economic Policy Institute. ILR Press, Ithaca, NY.

Switzer, Jeff. 2020. "COVID-19 Update: Further Metro Service Reductions Begin Saturday, April 18, to Support Essential Travel and Transit Workforce." Metro Matters Blog, King County Metro, April 16. 


\section{Figures and Tables}

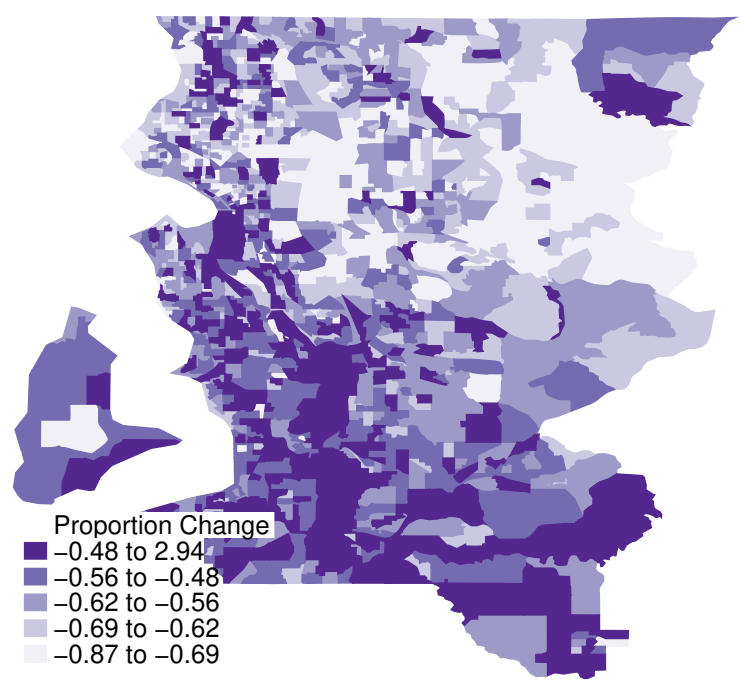

(a) Map of King County, WA

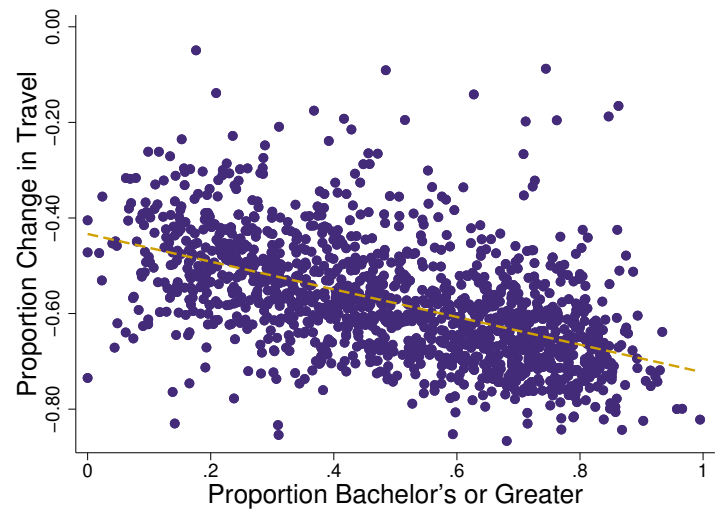

(b) Correlation with Neighborhood Education

Figure 1. Percent Change in Travel Intensity between April and February 2020, by Census Block Group

Notes: The unit of observation is census block group (CBG). Travel intensity is the number of other CBGs visited per device that usually resides in the given CBG, as measured by the SafeGraph Social Distancing Metrics dataset. Fraction with a bachelor's degree comes from the 2014-2018 5-year ACS estimates. To aid with presentation, some CBGs in eastern King County are omitted from the map, and a small number of CBGs with positive change in travel are omitted from the scatterplot. 


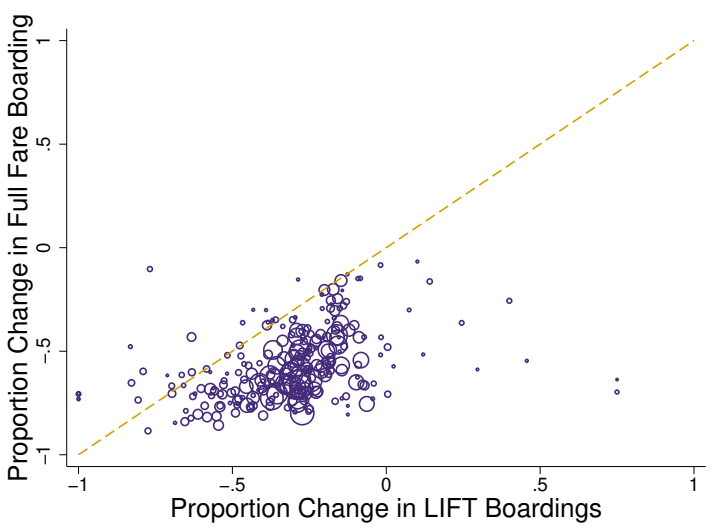

Figure 2. Percent Change in ORCA Boardings by Route, Base vs. Low-Income Fare

Notes: The unit of observation is a King County Metro route (almost always a bus route). The outcome includes only boardings paid for with an ORCA card, excluding cash and non-payment. Percent changes compare March 10-20 to February boardings. Reduced-fare LIFT versus full-fare boardings are detected by the payment type, which depends on the card serial number. The size of the circle is proportional to the sum of LIFT and full-fare boardings in February. We exclude routes that average less than 50 boardings per day in February to aid with presentation. 


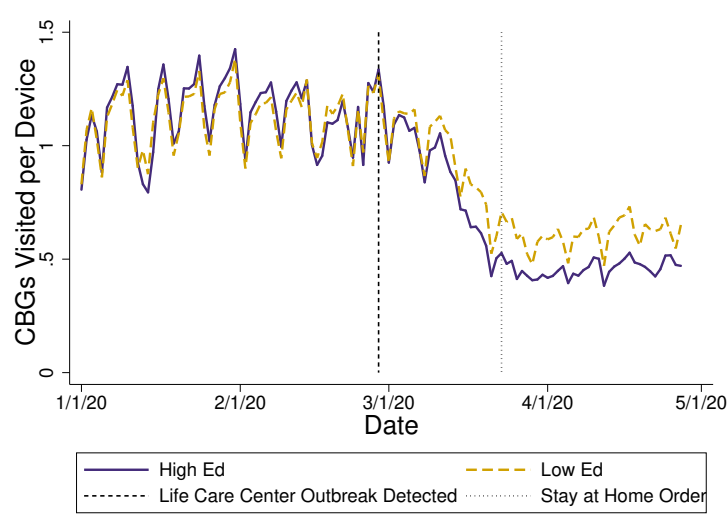

(a) Overall Travel by Nbd Education and Date

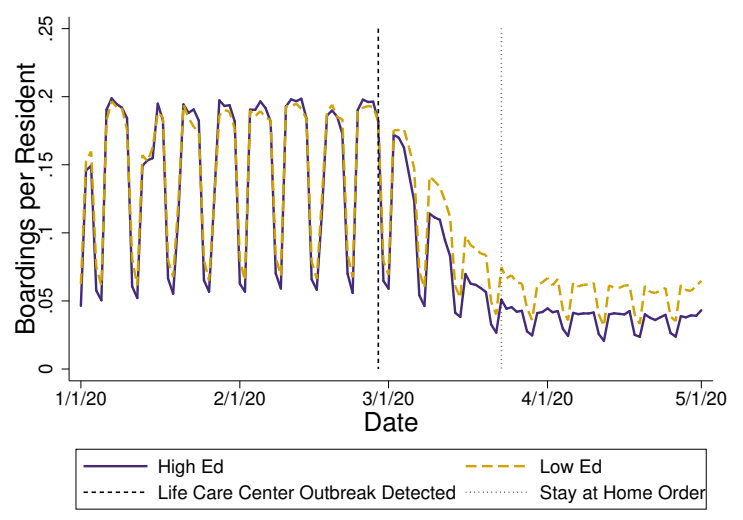

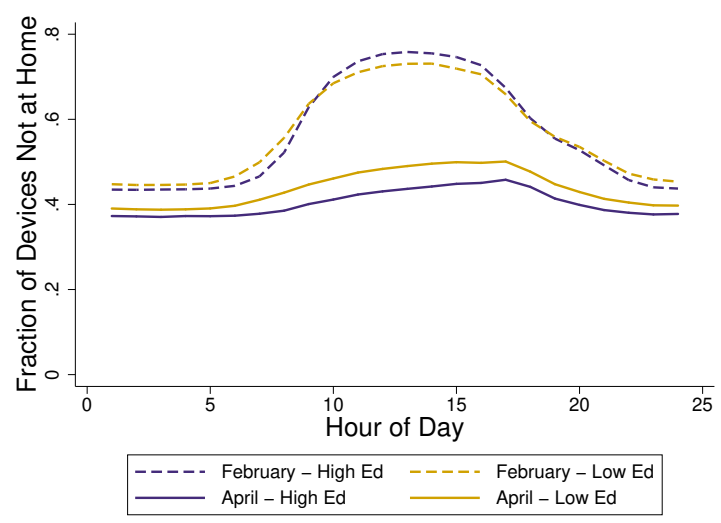

(d) Overall Travel by Nbd Education and Hour

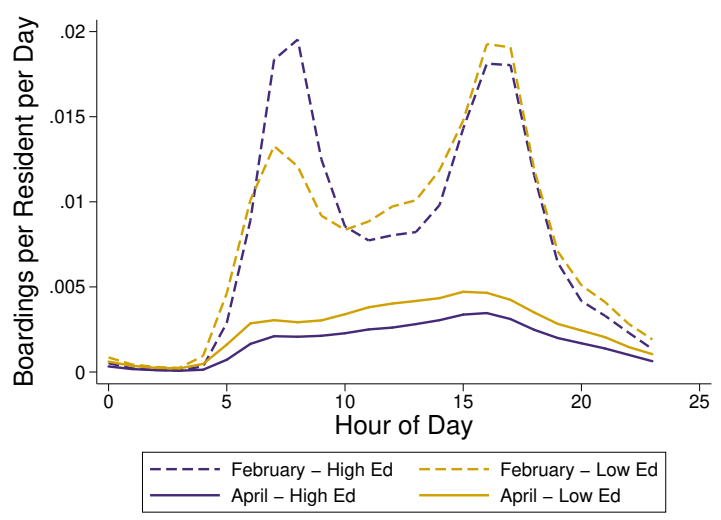

(b) Transit Boardings by Nbd Education and Date(e) Transit Boardings by Nbd Education and Hour

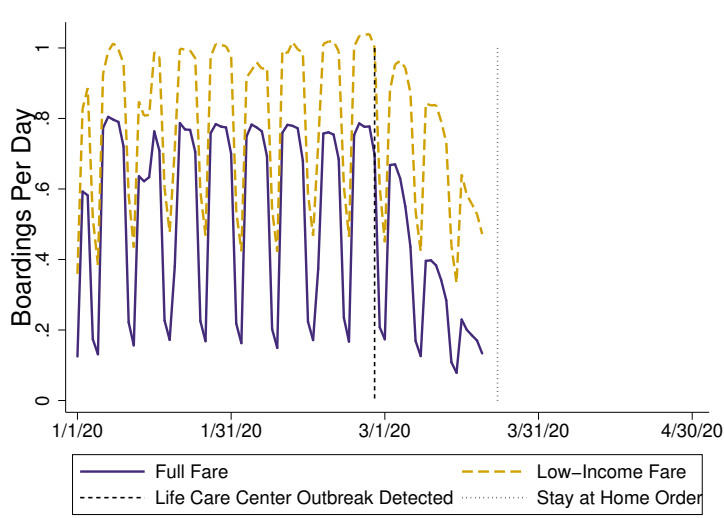

(c) Transit Boardings by Fare Type and Date

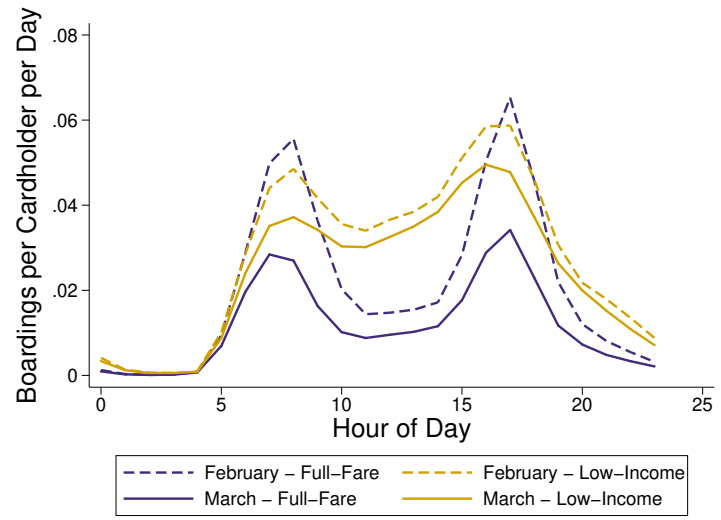

(f) Transit Boardings by Fare Type and Hour

Figure 3. Daily and Hourly Time Series of Travel in King County

Notes: The left column shows daily travel for all days and the right column shows hourly travel averaged over all weekdays in a month. Panels (a), (b), (d), and (e) compare census block groups (CBGs) based on whether they are above or below median for fraction with a bachelor's degree in the 2014-2018 ACS. Panels (a) and (d) use SafeGraph data on cell phone locations to track CBG visits per device and the fraction of devices not observed in their home CBG. Panels (b) and (e) show the same neighborhood comparison for transit boardings measured by automated passenger counters per population from the 2014-2018 ACS. Panels (c) and (f) show ORCA card boardings per card by whether the fare charged is the full adult fare or a reduce LIFT fare; the denominator is the number of cards ever used for that type of fare in January-March 2020. 


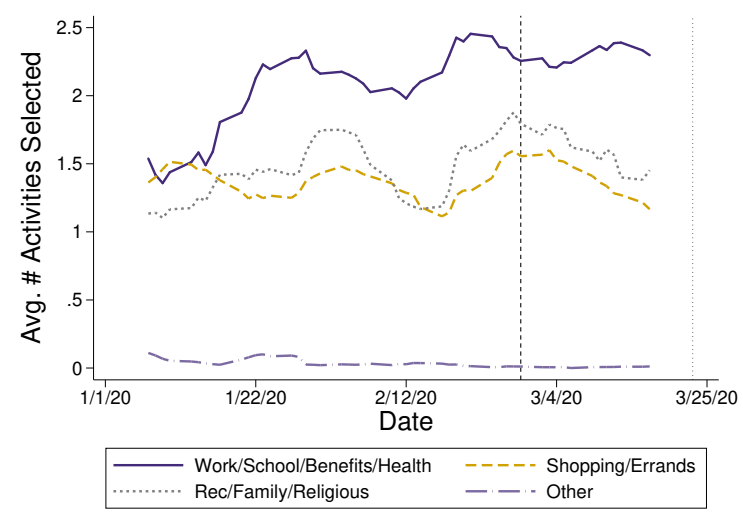

Figure 4. Intended Destinations of Low-Income Transit Users over Time, Survey Responses Notes: The data come from an intake survey for an ongoing study that provides subsidized transit fares. Respondents state the purposes for which they intend to use the subsidy. The outcome shown in the graph is the average number of items selected in that category for respondents completing the intake survey on a given day. 
Table 1. Correlates of Percent Change in Travel

\begin{tabular}{|c|c|c|c|c|c|c|c|}
\hline & $\begin{array}{c}(1) \\
\text { Safegraph } \\
\text { Travel }\end{array}$ & $\begin{array}{c}(2) \\
\text { Safegraph } \\
\text { Travel }\end{array}$ & $\begin{array}{c}(3) \\
\text { APC } \\
\text { Boardings }\end{array}$ & $\begin{array}{c}(4) \\
\text { APC } \\
\text { Boardings }\end{array}$ & $\begin{array}{c}(5) \\
\text { ORCA } \\
\text { Boardings }\end{array}$ & $\begin{array}{c}(6) \\
\text { ORCA } \\
\text { Boardings }\end{array}$ & $\begin{array}{c}(7) \\
\text { ORCA } \\
\text { Boardings }\end{array}$ \\
\hline Fraction Bachelor's & $\begin{array}{c}-0.30^{* * *} \\
(0.018)\end{array}$ & $\begin{array}{c}-0.17^{* * *} \\
(0.017)\end{array}$ & $\begin{array}{c}-0.31^{* * *} \\
(0.024)\end{array}$ & $\begin{array}{c}-0.19^{* * *} \\
(0.021)\end{array}$ & & & \\
\hline Weekday & & $\begin{array}{l}0.13^{* * *} \\
(0.0079)\end{array}$ & & $\begin{array}{c}0.20^{* * *} \\
(0.011)\end{array}$ & & & $\begin{array}{c}0.40^{* * *} \\
(0.046)\end{array}$ \\
\hline Frac Bac x Weekday & & $\begin{array}{c}-0.18^{* * *} \\
(0.013)\end{array}$ & & $\begin{array}{c}-0.15^{* * *} \\
(0.019)\end{array}$ & & & \\
\hline LIFT & & & & & $\begin{array}{c}0.19^{* * *} \\
(0.037)\end{array}$ & $\begin{array}{c}0.24^{* * *} \\
(0.035)\end{array}$ & $\begin{array}{c}0.11^{* * *} \\
(0.030)\end{array}$ \\
\hline LIFT x Weekday & & & & & & & $\begin{array}{l}0.10^{* *} \\
(0.052)\end{array}$ \\
\hline Constant & $\begin{array}{c}-0.42^{* * *} \\
(0.010)\end{array}$ & $\begin{array}{c}-0.52^{* * *} \\
(0.010)\end{array}$ & $\begin{array}{r}-0.58^{* * *} \\
(0.014)\end{array}$ & $\begin{array}{c}-0.73^{* * *} \\
(0.013)\end{array}$ & $\begin{array}{c}-0.51^{* * *} \\
(0.022)\end{array}$ & $\begin{array}{r}-0.49^{* * *} \\
(0.018)\end{array}$ & $\begin{array}{c}-0.83^{* * *} \\
(0.042)\end{array}$ \\
\hline Route FE & No & No & No & No & No & Yes & No \\
\hline Mean of Dep. Var. & -0.57 & -0.57 & -0.74 & -0.74 & -0.42 & -0.42 & -0.42 \\
\hline $\mathrm{R}^{2}$ & 0.092 & 0.11 & 0.039 & 0.064 & 0.0072 & 0.14 & 0.033 \\
\hline $\mathrm{N}$ & 38340 & 38340 & 35160 & 35160 & 6680 & 6680 & 6680 \\
\hline
\end{tabular}

Notes: Each column shows results from an OLS regression. Coefficients for all independent variables are shown unless noted in the table. The dependent variable in each column is the percent change in the outcome between the follow-up period and February. Columns (1)-(2) use SafeGraph data on the average number of other census block groups (CBGs) visited per device usually residing in the CBG as the outcome; columns (3)-(4) use transit boardings as measured by automated passenger counters; and columns (5)-(7) use transit boardings as measured by boardings paid for with an ORCA card. The unit of observation is the CBG-day in columns (1)-(4) and the route-day-fare type in columns (5)-(7); fare type is either LIFT or full adult fare. Fraction with a bachelor's degree comes from the 2014-2018 ACS. Each column covers all of King County, WA. The sample time period is April 2020 in columns (1)-(4) and March 10-20, 2020 in columns (5)-(7). Standard errors are clustered by CBG in columns (1)-(4) and by route in columns (5)-(7). Statistical significance at the 10,5 , and 1 percent level is denoted, respectively, by *, **, and ***. 


\section{Appendix Figures and Tables}

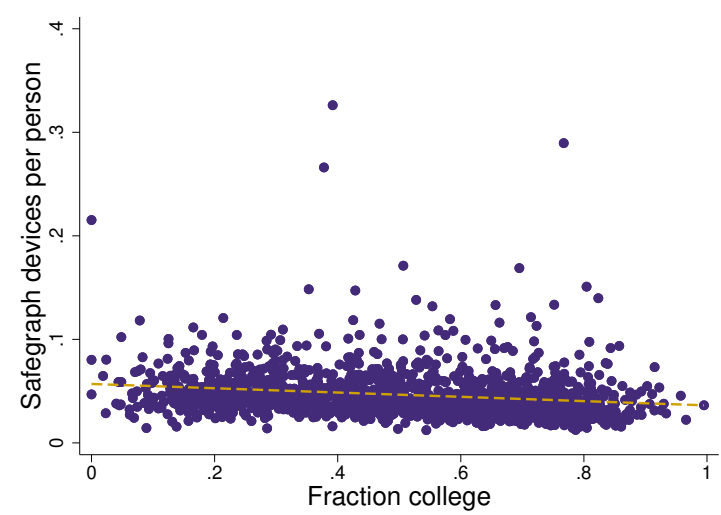

Figure A.1. Correlation of SafeGraph Device Prevalence with Education Levels, by CBG The unit of observation is census block group (CBG). Number of devices residing in the CBG is the average over January and February from the SafeGraph Social Distancing Metrics dataset. Total population and fraction with a bachelor's degree comes from the 2014-2018 5-year ACS estimates.

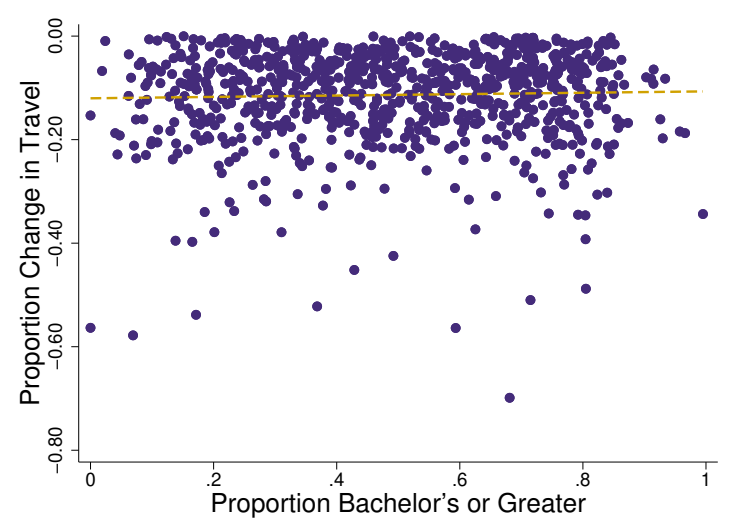

Figure A.2. Percent Change in Travel Intensity between January and February, by Census Block Group

The unit of observation is census block group (CBG). Travel intensity is the number of other CBGs visited per device that usually resides in the given CBG, as measured by the SafeGraph Social Distancing Metrics dataset. Fraction with a bachelor's degree comes from the 2014-2018 5-year ACS estimates. To be consistent with the main text, CBGs with positive change in travel are omitted from the scatterplot. 


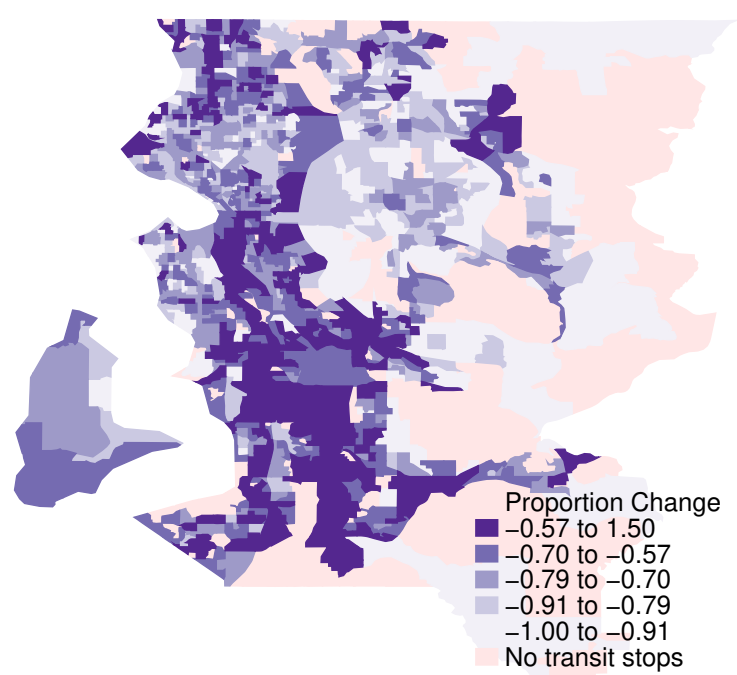

(a) Map of King County, WA

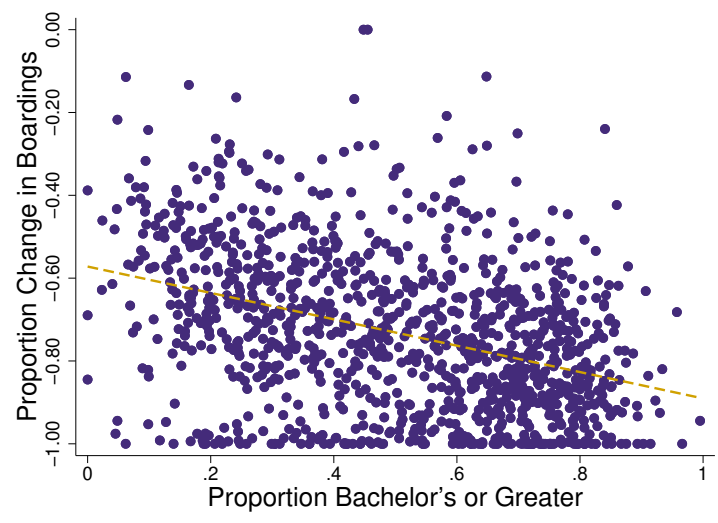

(b) Correlation with Neighborhood Education

Figure A.3. Percent Change in Transit Boardings between April and February, by Census Block Group

Notes: The unit of observation is census block group (CBG). Boardings come from King County Metro and are measured by automated passenger counters. Fraction with a bachelor's degree comes from the 2014-2018 5-year ACS estimates. To be consistent with the main text, some CBGs in eastern King County are omitted from the map, and CBGs with positive change in boardings are omitted from the scatterplot.

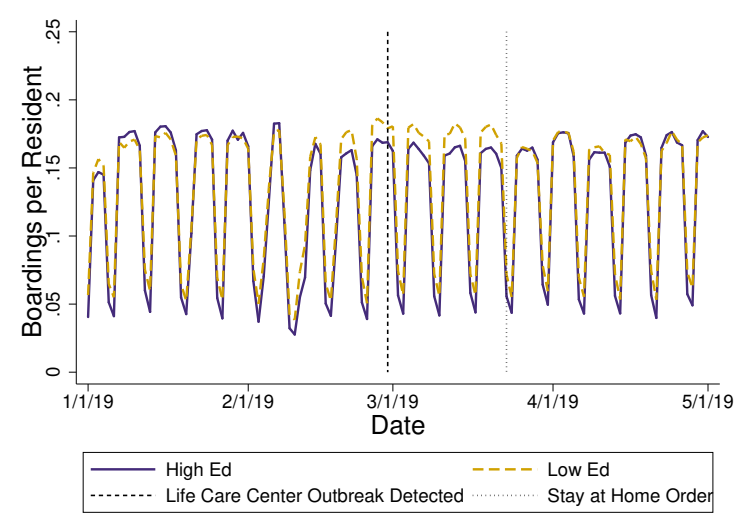

Figure A.4. Transit Boardings by Nbd Education and Date, 2019

Notes: The graph shows daily travel comparing census block groups (CBGs) based on whether they are above or below median for fraction with a bachelor's degree in the 2014-2018 ACS. It shows transit boardings measured by automated passenger counters per population from the 2014-2018 ACS. 
Table A.1. Correlates of Percent Change in Travel from a CBG, April vs Feb, SafeGraph

\begin{tabular}{lccccc}
\hline \hline & $(1)$ & $(2)$ & $(3)$ & $(4)$ & $(5)$ \\
& $\% \Delta$ Travel & $\% \Delta$ Travel & $\% \Delta$ Travel & $\% \Delta$ Travel & $\%$ Travel \\
\hline Fraction Bachelor's & $-0.30^{* * *}$ & & $-0.24^{* * *}$ & $-0.15^{* * *}$ & $-0.17^{* * *}$ \\
& $(0.018)$ & & $(0.021)$ & $(0.041)$ & $(0.017)$ \\
Median Income $(100 k)$ & & $-0.13^{* * *}$ & $-0.048^{* * *}$ & -0.023 & \\
& & $(0.011)$ & $(0.013)$ & $(0.017)$ & \\
Weekday & & & & $0.13^{* * *}$ \\
& & & & $(0.0079)$ \\
Weekday X Frac Bac & & & & $-0.18^{* * *}$ \\
& & & & & $(0.013)$ \\
Constant & $-0.42^{* * *}$ & $-0.45^{* * *}$ & $-0.40^{* * *}$ & $-0.83^{* * *}$ & $-0.52^{* * *}$ \\
& $(0.010)$ & $(0.014)$ & $(0.013)$ & $(0.23)$ & $(0.010)$ \\
Other CBG Characteristics & No & No & No & Yes & No \\
\hline Mean of Dep. Var. & -0.57 & -0.57 & -0.57 & -0.57 & -0.57 \\
$\mathrm{R}^{2}$ & 0.092 & 0.063 & 0.098 & 0.12 & 0.11 \\
$\mathrm{~N}$ & 38340 & 37854 & 37854 & 37854 & 38340 \\
\hline \hline
\end{tabular}

Notes: Each column shows results from an OLS regression. Coefficients for all independent variables are shown unless noted in the table. The dependent variable in each column is the percent change between February and April of SafeGraph data on the number of other census block groups (CBGs) visited per device usually residing in the CBG as the outcome. Each column covers all of King County, WA. The unit of observation is the CBG-day. Fraction with a bachelor's degree and median income come from the 2014-2018 ACS. Column (4) includes controls for 2014-2018 ACS values for the fraction of the CBG that is male, under 18, over 65, white, black, American Indian/Pacific Islander, Asian-American, Hispanic, moved in the past year, commuting 30+ minutes, commuting by transit, in families, in families with married head, in poverty, English-speaking, receiving public assistance, renting, employed, in the labor force, employed in various occupations, with a vehicle, a smartphone, a computer, and an internet connection. Standard errors are clustered by CBG. Statistical significance at the 10,5 , and 1 percent level is denoted, respectively, by *, **, and ***. 
Table A.2.Correlates of Percent Change in Travel from a CBG, Mid-March vs Feb, SafeGraph

\begin{tabular}{|c|c|c|c|c|c|}
\hline & $\begin{array}{c}(1) \\
\% \Delta \text { Travel }\end{array}$ & $\begin{array}{c}(2) \\
\% \Delta \text { Travel }\end{array}$ & $\begin{array}{c}(3) \\
\% \Delta \text { Travel }\end{array}$ & $\begin{array}{c}(4) \\
\% \Delta \text { Travel }\end{array}$ & $\begin{array}{c}(5) \\
\% \Delta \text { Travel }\end{array}$ \\
\hline Fraction Bachelor's & $\begin{array}{c}-0.31^{* * * *} \\
(0.017)\end{array}$ & & $\begin{array}{c}-0.28 * * * \\
(0.023)\end{array}$ & $\begin{array}{c}-0.20^{* * *} \\
(0.043)\end{array}$ & $\begin{array}{c}-0.12^{* * *} \\
(0.020)\end{array}$ \\
\hline Median Income $(100 k)$ & & $\begin{array}{l}-0.11^{* * *} \\
(0.0091)\end{array}$ & $\begin{array}{l}-0.016 \\
(0.011)\end{array}$ & $\begin{array}{l}-0.017 \\
(0.017)\end{array}$ & \\
\hline Weekday & & & & & $\begin{array}{l}0.14^{* * *} \\
(0.0091)\end{array}$ \\
\hline Weekday X Frac Bac & & & & & $\begin{array}{c}-0.23^{* * *} \\
(0.016)\end{array}$ \\
\hline Constant & $\begin{array}{l}-0.16^{* * *} \\
(0.0093)\end{array}$ & $\begin{array}{c}-0.21^{* * *} \\
(0.011)\end{array}$ & $\begin{array}{c}-0.16^{* * *} \\
(0.010)\end{array}$ & $\begin{array}{l}0.094 \\
(0.23)\end{array}$ & $\begin{array}{c}-0.28 * * * \\
(0.011)\end{array}$ \\
\hline Other CBG Characteristics & No & No & $\mathrm{No}$ & Yes & No \\
\hline $\begin{array}{l}\text { Mean of Dep. Var. } \\
\mathrm{R}^{2} \\
\mathrm{~N}\end{array}$ & $\begin{array}{l}-0.32 \\
0.084 \\
14200\end{array}$ & $\begin{array}{l}-0.32 \\
0.040 \\
14020\end{array}$ & $\begin{array}{l}-0.32 \\
0.083 \\
14020\end{array}$ & $\begin{array}{l}-0.32 \\
0.095 \\
14020\end{array}$ & $\begin{array}{l}-0.32 \\
0.093 \\
14200\end{array}$ \\
\hline
\end{tabular}

Notes: Each column shows results from an OLS regression. Coefficients for all independent variables are shown unless noted in the table. The dependent variable in each column is the percent change between February and mid-March of SafeGraph data on the number of other census block groups (CBGs) visited per device usually residing in the CBG as the outcome. Mid-March refers to March 11-20, 2020. Each column covers all of King County, WA. The unit of observation is the CBG-day. Fraction with a bachelor's degree and median income come from the 2014-2018 ACS. Column (4) includes controls for 2014-2018 ACS values for the fraction of the CBG that is male, under 18, over 65, white, black, American Indian/Pacific Islander, Asian-American, Hispanic, moved in the past year, commuting 30+ minutes, commuting by transit, in families, in families with married head, in poverty, English-speaking, receiving public assistance, renting, employed, in the labor force, employed in various occupations, with a vehicle, a smartphone, a computer, and an internet connection. Standard errors are clustered by CBG. Statistical significance at the 10, 5 , and 1 percent level is denoted, respectively, by *,**, and ***. 
Table A.3. Correlates of Percent Change in Transit Boardings from a CBG, April vs Feb

\begin{tabular}{|c|c|c|c|c|c|}
\hline & $\begin{array}{c}(1) \\
\% \Delta \text { Travel }\end{array}$ & $\begin{array}{c}(2) \\
\% \Delta \text { Travel }\end{array}$ & $\begin{array}{c}(3) \\
\% \Delta \text { Travel }\end{array}$ & $\begin{array}{c}(4) \\
\% \Delta \text { Travel }\end{array}$ & $\begin{array}{c}(5) \\
\% \Delta \text { Travel }\end{array}$ \\
\hline Fraction Bachelor's & $\begin{array}{c}-0.31^{* * * *} \\
(0.024)\end{array}$ & & $\begin{array}{c}-0.18^{* * *} \\
(0.030)\end{array}$ & $\begin{array}{r}-0.0046 \\
(0.061)\end{array}$ & $\begin{array}{c}-0.19^{* * *} \\
(0.021)\end{array}$ \\
\hline Median Income $(100 k)$ & & $\begin{array}{c}-0.17^{* * *} \\
(0.013)\end{array}$ & $\begin{array}{c}-0.11^{* * *} \\
(0.016)\end{array}$ & $\begin{array}{l}-0.022 \\
(0.026)\end{array}$ & \\
\hline Weekday & & & & & $\begin{array}{c}0.20^{* * *} \\
(0.011)\end{array}$ \\
\hline Weekday X Frac Bac & & & & & $\begin{array}{c}-0.15^{* * *} \\
(0.019)\end{array}$ \\
\hline Other CBG Characteristics & No & No & No & Yes & No \\
\hline Mean of Dep. Var. & -0.74 & -0.74 & -0.74 & -0.74 & -0.74 \\
\hline $\mathrm{R}^{2}$ & 0.039 & 0.041 & 0.049 & 0.074 & 0.064 \\
\hline $\mathrm{N}$ & 35160 & 34650 & 34650 & 34650 & 35160 \\
\hline
\end{tabular}

Notes: Each column shows results from an OLS regression. Coefficients for all independent variables are shown unless noted in the table. The dependent variable in each column is the percent change between February and April of King County Metro data on the number of transit boardings measured by automated passenger counters as the outcome. Each column covers all of King County, WA. The unit of observation is the CBG-day. Fraction with a bachelor's degree and median income come from the 2014-2018 ACS. Column (4) includes controls for 2014-2018 ACS values for the fraction of the CBG that is male, under 18, over 65, white, black, American Indian/Pacific Islander, Asian-American, Hispanic, moved in the past year, commuting 30+ minutes, commuting by transit, in families, in families with married head, in poverty, English-speaking, receiving public assistance, renting, employed, in the labor force, employed in various occupations, with a vehicle, a smartphone, a computer, and an internet connection. Standard errors are clustered by CBG. Statistical significance at the 10,5 , and 1 percent level is denoted, respectively, by *,**, and $* * *$. 
Table A.4. Correlates of Percent Change in Transit Boardings from a CBG, Mid-March vs Feb

\begin{tabular}{|c|c|c|c|c|c|}
\hline & $\begin{array}{c}(1) \\
\% \Delta \text { Travel }\end{array}$ & $\begin{array}{c}(2) \\
\% \Delta \text { Travel }\end{array}$ & $\% \Delta^{(3)}$ Travel & $\% \Delta^{(4)}$ Travel & $\begin{array}{c}(5) \\
\% \Delta \text { Travel }\end{array}$ \\
\hline Fraction Bachelor's & $\begin{array}{c}-0.50^{* * *} \\
(0.030)\end{array}$ & & $\begin{array}{c}-0.47^{* * *} \\
(0.046)\end{array}$ & $\begin{array}{c}-0.21^{* *} \\
(0.094)\end{array}$ & $\begin{array}{c}-0.31^{* * *} \\
(0.032)\end{array}$ \\
\hline Median Income $(100 k)$ & & $\begin{array}{c}-0.19 * * * \\
(0.021)\end{array}$ & $\begin{array}{l}-0.028 \\
(0.029)\end{array}$ & $\begin{array}{l}0.0053 \\
(0.046)\end{array}$ & \\
\hline Weekday & & & & & $\begin{array}{c}0.43^{* * * *} \\
(0.027)\end{array}$ \\
\hline Weekday X Frac Bac & & & & & $\begin{array}{c}-0.24^{* * *} \\
(0.041)\end{array}$ \\
\hline Other CBG Characteristics & No & No & $\mathrm{No}$ & Yes & $\mathrm{No}$ \\
\hline Mean of Dep. Var. & -0.44 & -0.44 & -0.44 & -0.44 & -0.44 \\
\hline $\mathrm{R}^{2}$ & 0.026 & 0.013 & 0.026 & 0.034 & 0.058 \\
\hline $\mathrm{N}$ & 11720 & 11550 & 11550 & 11550 & 11720 \\
\hline
\end{tabular}

Notes: Each column shows results from an OLS regression. Coefficients for all independent variables are shown unless noted in the table. The dependent variable in each column is the percent change between February and mid-March of King County Metro data on the number of transit boardings measured by automated passenger counters as the outcome. Mid-March refers to March 11-20, 2020. Each column covers all of King County, WA. The unit of observation is the CBG-day. Fraction with a bachelor's degree and median income come from the 2014-2018 ACS. Column (4) includes controls for 2014-2018 ACS values for the fraction of the CBG that is male, under 18, over 65, white, black, American Indian/Pacific Islander, Asian-American, Hispanic, moved in the past year, commuting 30+ minutes, commuting by transit, in families, in families with married head, in poverty, English-speaking, receiving public assistance, renting, employed, in the labor force, employed in various occupations, with a vehicle, a smartphone, a computer, and an internet connection. Standard errors are clustered by CBG. Statistical significance at the 10, 5 , and 1 percent level is denoted, respectively, by *, **, and ***. 
Table A.5. Correlates of Percent Change in Transit Boardings, Mid-March vs Feb, ORCA Boardings

\begin{tabular}{lccc}
\hline \hline & $(1)$ & $(2)$ & $(3)$ \\
& \% Change Travel & \% Change Travel & \% Change Travel \\
\hline LIFT & $0.19^{* * *}$ & $0.24^{* * *}$ & $0.11^{* * *}$ \\
& $(0.037)$ & $(0.035)$ & $(0.030)$ \\
Weekday & & & $0.40^{* * *}$ \\
& & & $(0.046)$ \\
LIFT x Weekday & & & $0.10^{* *}$ \\
& & & $(0.052)$ \\
Constant & $-0.51^{* * *}$ & $-0.49^{* * *}$ & $-0.83^{* * *}$ \\
& $(0.022)$ & $(0.018)$ & $(0.042)$ \\
Route FE & No & Yes & No \\
\hline Mean of Dep. Var. & -0.42 & -0.42 & -0.42 \\
$\mathrm{R}^{2}$ & 0.0072 & 0.14 & 0.033 \\
$\mathrm{~N}$ & 6680 & 6680 & 6680 \\
\hline \hline
\end{tabular}

Notes: Each column shows results from an OLS regression. Coefficients for all independent variables are shown unless noted in the table. The dependent variable in each column is the percent change between February and mid-March of King County Metro data on the number of transit boardings measured by fares paid with an ORCA card as the outcome. Mid-March refers to March 11-20, 2020. Each column covers all of King County, WA. The unit of observation is the route-day-fare type. Fare types are either the low-income LIFT fare or the full adult fare. Standard errors are clustered by route. Statistical significance at the 10,5 , and 1 percent level is denoted, respectively, by ${ }^{*}, * *$, and $* * *$. 
Table A.6. Correlates of Percent Change in Transit Boardings, Mid-March vs Feb, ORCA Boardings

\begin{tabular}{lcccccccc}
\hline \hline & $(1)$ & $(2)$ & $(3)$ & $(4)$ & $(5)$ & $(6)$ & $(7)$ & $(8)$ \\
& Peak AM & Peak AM & Peak PM & Peak PM & Off AM & Off AM & Off PM & Off PM \\
\hline LIFT & 0.016 & $0.043^{* * *}$ & $0.062^{* * *}$ & $0.078^{* * *}$ & $0.10^{* * *}$ & $0.10^{* * *}$ & 0.0086 & $0.014^{* * *}$ \\
& $(0.012)$ & $(0.0096)$ & $(0.016)$ & $(0.017)$ & $(0.030)$ & $(0.030)$ & $(0.0083)$ & $(0.0051)$ \\
Constant & $-0.82^{* * *}$ & $-0.87^{* * *}$ & $-0.80^{* * *}$ & $-0.82^{* * *}$ & $-0.93^{* * *}$ & $-0.86^{* * *}$ & $-0.96^{* * *}$ & $-0.95^{* * *}$ \\
& $(0.0096)$ & $(0.0048)$ & $(0.012)$ & $(0.0084)$ & $(0.0071)$ & $(0.015)$ & $(0.011)$ & $(0.0025)$ \\
Route FE & No & Yes & No & Yes & No & Yes & No & Yes \\
\hline Mean of Dep. Var. & -0.81 & -0.81 & -0.77 & -0.77 & -0.88 & -0.88 & -0.96 & -0.96 \\
$\mathrm{R}^{2}$ & 0.00041 & 0.17 & 0.0024 & 0.073 & 0.0056 & 0.16 & 0.00012 & 0.18 \\
$\mathrm{~N}$ & 6680 & 6680 & 6680 & 6680 & 6680 & 6680 & 6680 & 6680 \\
\hline \hline
\end{tabular}

Notes: Each column shows results from an OLS regression. Coefficients for all independent variables are shown unless noted in the table. The dependent variable in each column is the percent change between February and mid-March of King County Metro data on the number of transit boardings measured by fares paid with an ORCA card as the outcome. Mid-March refers to March 11-20, 2020. Each column covers all of King County, WA but restricts the outcome to boardings occuring during a certain time of the day. The unit of observation is the route-day-fare type. Fare types are either the low-income LIFT fare or the full adult fare. Standard errors are clustered by route. Statistical significance at the 10, 5 , and 1 percent level is denoted, respectively, 
Table A.7. Descriptive Statistics for Travel Survey

\begin{tabular}{|c|c|c|}
\hline & $\begin{array}{c}\text { Study Population } \\
\text { Mean/SE }\end{array}$ & $\begin{array}{c}\text { Follow-up Survey } \\
\text { Responders } \\
\text { Mean/SE }\end{array}$ \\
\hline \multicolumn{3}{|l|}{ Intake Survey } \\
\hline Age & $\begin{array}{c}40.4 \\
(13.1)\end{array}$ & $\begin{array}{c}40.2 \\
(13.6)\end{array}$ \\
\hline Travel Intention: Number of Essential Destinations & $\begin{array}{c}2.00 \\
(1.26)\end{array}$ & $\begin{array}{c}2.13 \\
(1.21)\end{array}$ \\
\hline Travel Intention: Number of Commercial Destinations & $\begin{array}{c}1.32 \\
(0.77)\end{array}$ & $\begin{array}{c}1.36 \\
(0.82)\end{array}$ \\
\hline Travel Intention: Number of Social Destinations & $\begin{array}{c}1.39 \\
(1.15)\end{array}$ & $\begin{array}{c}1.50 \\
(1.16)\end{array}$ \\
\hline Travel Intention: Number of Other Destinations & $\begin{array}{l}0.061 \\
(0.24)\end{array}$ & $\begin{array}{l}0.050 \\
(0.22)\end{array}$ \\
\hline Days Used Public Transit in Past Month & $\begin{array}{c}15.6 \\
(10.9)\end{array}$ & $\begin{array}{c}16.2 \\
(10.9)\end{array}$ \\
\hline Value of a Monthly Transit Pass & $\begin{array}{c}14.8 \\
(18.9)\end{array}$ & $\begin{array}{l}17.1 \\
(20.6)\end{array}$ \\
\hline Follow-up Survey & & \\
\hline Total Trips Taken & & $\begin{array}{l}2.09 \\
(2.27)\end{array}$ \\
\hline Total Trips Taken in Feb & & $\begin{array}{c}2.96 \\
(4.15)\end{array}$ \\
\hline Never Left Home & & $\begin{array}{c}0.37 \\
(0.48)\end{array}$ \\
\hline Number of Essential Trips & & $\begin{array}{c}0.58 \\
(1.07)\end{array}$ \\
\hline Number of Commercial Trips & & $\begin{array}{c}0.84 \\
(1.41)\end{array}$ \\
\hline Number of Social/Other Trips & & $\begin{array}{c}0.67 \\
(1.50)\end{array}$ \\
\hline Observations & 1318 & 119 \\
\hline
\end{tabular}

Notes: The data come from an ongoing study that provides subsidized transit fares. The top panel reports variables from an intake survey. The bottom panel shows variables measured through a phone and web survey conducted 1-3 months later. 